\section{Classificação do Carcinoma Diferenciado de Tireóide Baseada no Prognóstico. Qual e Quando Usar?}

V ÁrIAs ClassificaÇÕes são pRopostas para o carcinoma diferenciado de tireóide (CDT) com base em variáveis independentes de prognóstico. A utilização de estadiamentos diferentes dificulta a comparação de resultados de publicações e, em parte, a aplicação plena dos achados em pacientes classificados de forma distinta. Apesar de alguns estudos demonstrarem diferenças na acurácia em situações específicas, de maneira geral estas classificações correlacionam muito bem com o prognóstico do CDT (1).

American Joint Committee on Cancer (AJCC) / Tumor Nodes Metastasis (TNM) (2), classificação mundialmente usada para os tumores malignos, é bem conhecida, tem ampla abrangência das variáveis implicadas no prognóstico do CDT, guardando uma correlação estreita com a evolução da doença $(1,3,4)$. Apesar de imperfeições, esta é a forma de estadiamento atualmente recomendada $(1,3,4)$ e que sugerimos como padronização aos diversos serviços em nosso país. A tabela 1 mostra o estadiamento do CDT pela AJCC/TNM.

Avaliamos 168 pacientes com CDT acompanhados por, pelo menos, 5 anos após a terapia inicial (tireoidectomia total seguida de radioiodoterapia em todos) e classificados pela AJCC/TNM em estadiamento I (qualquer $\mathrm{T}$, qualquer $\mathrm{N}, \mathrm{M} 0$ se $<45$ anos e TIN0M0 se $\geq 45$ anos) em 62 ; II (metástases distantes se $<45$ anos e T2-3N0M0 se $\geq 45$ anos) em 36; III (T4N0M0 ou qualquer T NIM0 em $\geq 45$ anos) em 40; e IV (metástases distantes em $\geq 45$ anos) em 30 . A taxa de mortalidade e de pacientes livres de doença em 6,1 anos, em média, são apresentados na tabela 2 .

Além do prognóstico, o estadiamento tem um papel importante na definição terapêutica e no seguimento dos pacientes após a terapia inicial. Sabemos que pacientes de baixo risco (estadiamento I se $<45$ anos e I e II se $\geq 45$ anos) podem ser avaliados inicialmente apenas com a tireoglobulina sérica estimulada, tendo este marcador um alto valor preditivo negativo (5). E casos classificados como TIN0M0 não se beneficiam da radioiodoterapia pós-operatória, do ponto de vista de recorrência, aparecimento de metástases e mortalidade (4).

Na Santa Casa de Belo Horizonte, dos pacientes considerados de baixo risco e procedentes de diferentes serviços para a realização de varredura com radioiodo após o tratamento inicial, 70\% apresentam $\mathrm{Tg}$ em hipotireoidismo $<2 \mathrm{ng} / \mathrm{ml}$, dosada no momento da varredura, o que demonstra uma rotina ainda presente de solicitação conjunta de $\mathrm{Tg}$ e varredura durante o hipotireoidismo, o que aumenta desnecessariamente o custo da avaliação nestes casos. E, considerando que pacientes TIN0M0 não se beneficiam da radioiodoterapia, 16\% dos casos tratados neste serviço, a princípio, não deveriam receber radioiodo, e a maioria foi tratada com altas doses de iodo 131 (3,7GBq). Schlumberger já havia chamado a atenção que cerca de $1 / 4$ a 1/3 dos casos de CDT não tinham indicação de radioiodoterapia (6).

Defendemos que a classificação AJCC/TNM seja padronizada no CDT e, mais importante, seja aplicada na definição do tratamento inicial e seguimento dos pacientes, reduzindo custos e poupando-os de eventuais efeitos diversos.

\section{cartas ao editor}

\author{
Pedro Weslley S. do Rosário
}


Tabela 1. Classificação AJCC/TNM do carcinoma diferenciado de tireóide.

\begin{tabular}{lll}
\hline & $<45$ anos & $\geq 45$ anos \\
\hline Estadiamento I & qualquer T ou N, M0 & T1NOMO \\
Estadiamento II & qualquer T ou N, M1 & T2 ou T3, NOM0 \\
Estadiamento III & & T4NOMO ou qualquer T, N1M0 \\
Estadiamento IV & & qualquer T ou N, M1 \\
\hline
\end{tabular}

T1: tumor primário $\leq 1 \mathrm{~cm}$; T2: >1 e $\leq 4 \mathrm{~cm}$; T3: >4cm; T4: qualquer tamanho com invasão de cápsula tireoideana.

NO: sem metástases linfonodais; N1: com metástases linfonodais.

M0: sem metástases distantes; M1: com metástases distantes.

Tabela 2. Taxa de mortalidade e de pacientes livres de doença de acordo com o estadiamento do CDT.

\begin{tabular}{ccc}
\hline Estadiamento AJCC/TNM & Mortalidade & Pacientes considerados livres de doença \\
\hline I & $0 \%$ & $95 \%$ \\
II & $0 \%$ & $86 \%$ \\
III & $5 \%$ & $50 \%$ \\
IV & $33 \%$ & $30 \%$ \\
\hline
\end{tabular}

\section{REFERÊNCIAS}

1. Brierley JD, Panzarella T, Tsang RW, Gospodarowick MK, O'Sullivan B. A comparison of different staging systems predictability of patient outcome. Thyroid carcinoma as an example. Cancer 1997;79:2414-23.

2. American Joint Committee on Cancer. Cancer Stating Manual, $5^{\text {th }}$ ed. Philadelphia: Lippincott-Raven, 1997.

3. Mazzaferri EL. NCCN thyroid carcinoma practice guidelines. Oncology 1999; 13 (suppl. 11A):391-442.

4. AACE/AAES medical/surgical guidelines for clinical practice: management of thyroid carcinoma. American Association of Clinical Endocrinologists. American College of Endocrinology. Endocrinol Pract 2001;7:202-20.

5. Mazzaferri EL, Robbins RJ, Spencer CA, Braverman LE, Pacini F, Wartofsky L, et al. A consensus report of the role of serum thyroglobulin as a monitoring method for lowrisk patients with papillary thyroid carcinoma. J Clin Endocrinol Metab 2003;88:1433-41.

6. Schlumberger M. Use of radioactive iodine in patients with papillary and follicular thyroid cancer: towards a selective approach. J Clin Endocrinol Metab 1998;83:4201-3.

\section{Endereço para correspondência:}

Pedro W.S. Rosário

Centro de Estudos e Pesquisa

da Clínica de Endocrinologia e Metabologia (CEPCEM)

Av. Francisco Sales $1111,5^{\circ}$ andar, ala "D"

30150-221 Belo Horizonte, MG

E-mail: cepcem.bhz@zaz.com.br 